\title{
Bile duct injury during laparoscopic cholecystectomy: An Indian e-survey
}

\author{
Supriya Sharma, Anu Behari, Ratnakar Shukla, Mukteshwar Dasari, and Vinay K. Kapoor \\ Department of Surgical Gastroenterology, Sanjay Gandhi Postgraduate Institute of Medical Sciences, \\ Lucknow, UP, India
}

\begin{abstract}
Backgrounds/Aims: In the absence of national registry of laparoscopic cholecystectomy (LC) or its complications, it is impossible to determine incidence of bile duct injury (BDI) in India. We conducted an e-survey among practicing surgeons to determine prevalence and management patterns of BDI in India. Our hypothesis was that majority of surgeons would have experienced a BDI during LC despite large experience and that most surgeons who have a BDI tend to manage it themselves. Methods: An 18-question e-survey of practicing laparoscopic surgeons in India was done. Results: $278 / 727$ (38\%) surgeons responded. $240 / 278$ (86\%) respondents admitted to a BDI during LC and $179 / 230(78 \%)$ affirmed to more than one BDI. A total of $728 \mathrm{BDIs}$ were reported. $36 / 230(15 \%)$ respondents experienced their first BDI even after $>10$ years of practice and $40 \%$ had their first BDI even after having performed $>100$ LCs. $161 / 201(80 \%)$ of the respondents decided to manage the BDI themselves, including $56 / 99(57 \%)$ non-biliary surgeons and 44/82 (54\%) surgeons working in non-biliary center. 37/201 (18\%) respondents admitted to having a mortality arising out of a BDI; the mortality rate of BDI was $37 / 728(5 \%)$ in this survey. Only $13 / 201(6 \%)$ respondents have experienced a medico-legal case related to a BDI during LC. Conclusions: Prevalence of BDI is high in India and occurs despite adequate experience and volume. Even inexperienced non-biliary surgeons working in non-biliary centers attempt to repair the BDI themselves. BDI is associated with significant mortality but litigation rates are fortunately low in India. (Ann Hepatobiliary Pancreat Surg 2020;24:469-476)
\end{abstract}

Key Words: Laparoscopic cholecystectomy; Bile duct injury; E-survey; Prevalence; Bile leak

\section{INTRODUCTION}

Laparoscopic cholecystectomy (LC) has become standard surgical treatment for gallstone disease. There is a wide range $(0.5 \%$ to $1.5 \%)$ of incidence of BDI during $\mathrm{LC},{ }^{1,2}$ compared to $0.3 \%$ for open cholecystectomy (OC). ${ }^{3}$ Incidence (number of BDIs divided by number of LCs) data is available from countries in Europe and USA where population and registry data is available., ${ }^{2,4}$ With a population of about 1.3 billion, a large number of LCs are performed in India. It is not possible to document incidence of BDI since there is no national registry of LC or its complications. Prevalence (number of surgeons who had a BDI divided by number of surgeons doing LC) data is available from surveys in many western and developed countries including USA, ${ }^{5}$ Canada, ${ }^{6}$ Italy, ${ }^{7}$ Sweden, ${ }^{8}$ UK, ${ }^{9}$
Japan, Korea and Taiwan, ${ }^{10}$ but there are no studies from low-middle income countries (LMIC), including India.

We conducted an e-survey amongst practicing surgeons to find out prevalence and management patterns of BDI in India. We hypothesized that majority of surgeons in India continue to experience a BDI during LC even after adequate experience with LC. We also hypothesized that most surgeons who have a BDI tend to manage it themselves.

\section{MATERIALS AND METHODS}

\section{Questionnaire}

An anonymous $\mathrm{e}^{-}$-survey was developed using Survey Monkey ${ }^{\circledR}$, an online survey development cloud-based software (www.surveymonkey.com). 17 questions were closed 
type (multiple choices) and 1 was free response type (open ended). The questions were self-explanatory, but any doubts raised by the respondents were clarified by the authors on email/over phone. Four professors reviewed the questions and confirmed them to be representative of the content validity of the survey. The survey was filled twice by different individuals to identify errors in wording, grammar or syntax. The 'Logics' feature on Survey Monkey ${ }^{\circledR}$ allowed the respondents to skip to a specific question based on their answer to a previous close-ended question. The respondents could skip the questions they didn't want to answer or change their answers before the final submission. The average survey response time was five minutes. Internet Protocol addresses were checked to avoid duplication of responses.

Four questions aimed to establish the nature of practice of the surgeon viz. private setup, corporate hospital or institute-based practice (Q 1) and the experience with LC (Q 2) and whether the respondent surgeon is a biliary or non-biliary surgeon (Q 16), working in a biliary or nonbiliary center ( $Q$ 17). The respondents were then asked if they have ever had a post-cholecystectomy BDI (Q 3) and whether they have had more than one BDI (Q 4). We asked them to report a BDI during LC either done by them or supervised by them and not to include BDIs occurring in the hands of other surgeons/units and referred to them for definitive management. Respondents who admitted to a BDI during LC were then taken through questions to ascertain number of years of laparoscopic surgery experience (Q 5) and number of LCs (Q 6), specifically prior to their first BDI. Responses were obtained regarding associated bilio-vascular injury (BVI) (Q 7), use of intraoperative cholangiography (IOC) (Q 8), time of detection of BDI (intraoperative, postoperative or follow-up) (Q 9), respondent's role in the operating team in the LC i.e. chief operating surgeon, assisting senior surgeon as junior colleague, assisting junior surgeon as senior colleague or leader of operating team (even if not scrubbed in the case) (Q 10), choice of management (self-management or referral) (Q 11), management strategy (Q 12), any BDI during laparoscopic converted to open or open cholecystectomy (Q 13), any mortality related to BDI (Q 14) and any medico-legal litigation arising out of the BDI (Q 15). The last question ( $Q$ 18) was a text-based question which aimed to collect similar information regarding sub- sequent BDIs. The questionnaire is attached (Supplement 1).

In order to attain uniformity we used the following definitions; these were explained to the respondents on phone/ email, in case they had any doubts.

\section{Bile duct injury}

1. Unexplained intraoperative visualization of bile.

2. Visualization of bile in the drain placed intraoperatively.

3. Visualization of bile in a percutaneous catheter drain (PCD) placed postoperatively.

4. Surgical obstructive jaundice due to benign biliary stricture (BBS).

\section{Biliary surgeon}

A surgeon who performs elective hepatico-jejunostomy on a regular and frequent basis.

\section{Biliary center}

A facility where infrastructure and expertise for interventional radiology, therapeutic endoscopy and biliary reconstructive surgery are available.

\section{Survey population}

The senior author (VKK) emailed members of Uttar Pradesh State Chapter of Association of Surgeons of India (UPASI), Society of Endoscopic and Laparoscopic Surgeons of India (SELSI), faculty members in institutions offering superspecialty training programs in surgical gastroenterology and alumni of our department over last three decades explaining the purpose of the survey. The respondents were invited to click on the embedded question or the hypertext link, which invoked the web browser and presented the web-based questionnaire. Once completed by the respondents, the questionnaires were transmitted anonymously to the sender. Responses were received by email in a format which enabled transfer to Microsoft Excel and SPSS. The respondents were assured of complete anonymity and informed that their responses would be collated for analysis for presentation/ publication; no incentives were offered. The eligible participants were given 5 weeks' to complete the questionnaire from 24. 4. 2020 till 30. 5. 2020.

Exemption from review was obtained from the institutional ethics committee (2018-62-IP-EXP) of Sanjay Gandhi 


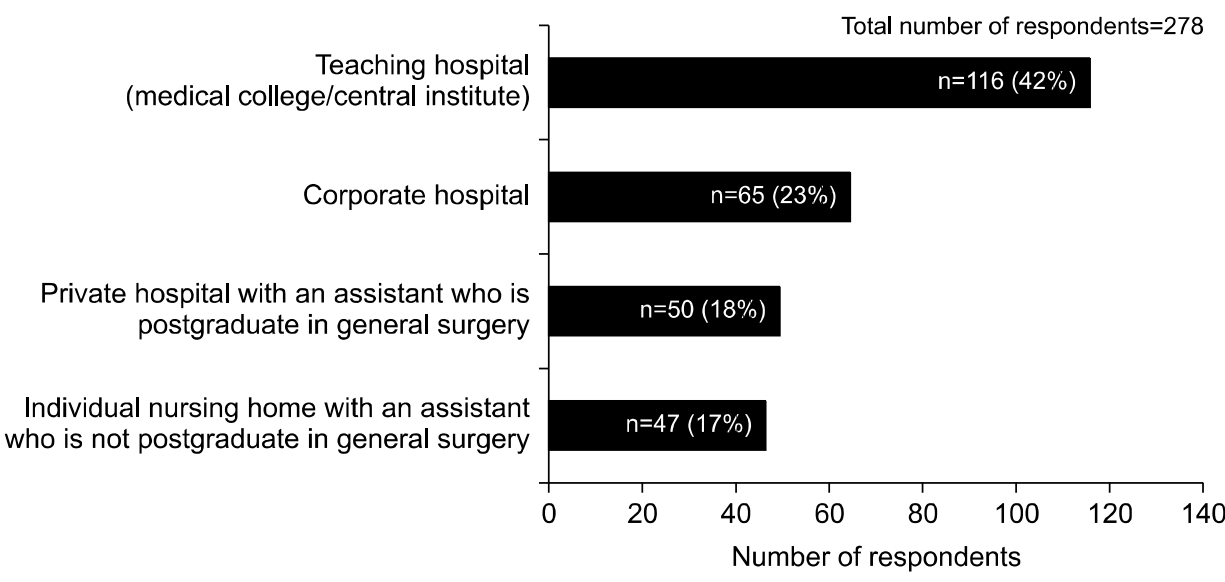

Fig. 1. Bar chart to show the demography of surgical practice of respondents.

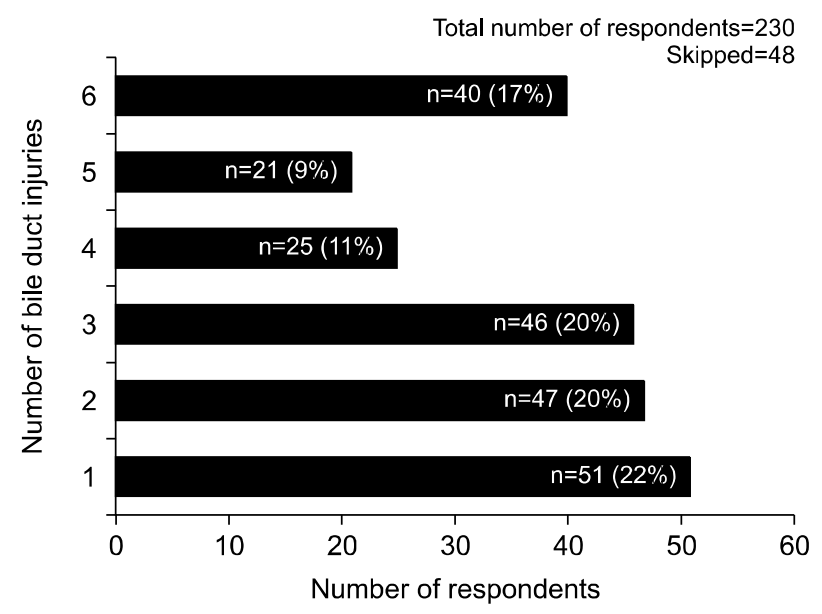

Fig. 2. Bar chart to show number of bile duct injuries experienced by the respondents.

Post Graduate Institute of Medical Sciences (SGPGIMS), Lucknow India. We adhered to the Checklist for Reporting Results of Internet E-surveys to report the data. ${ }^{11}$

\section{RESULTS}

A total of 2,916 emails were sent, 727 persons opened the survey and we received 179 responses over email and 99 responses via the web link. The overall response rate of survey was 278/727 (38\%).

Fig. 1 shows the demography of surgical practice of respondents (Q 1). 132/278 (47\%) respondents had more than 15 years of experience in LC (Q 2). 102/201 (51\%) were biliary surgeons (Q 16) and 119/201 (59\%) worked in a biliary center (Q 17).

As many as $240 / 278(86 \%)$ of respondents had experienced at least one BDI in their practice (Q 3) and 179/230

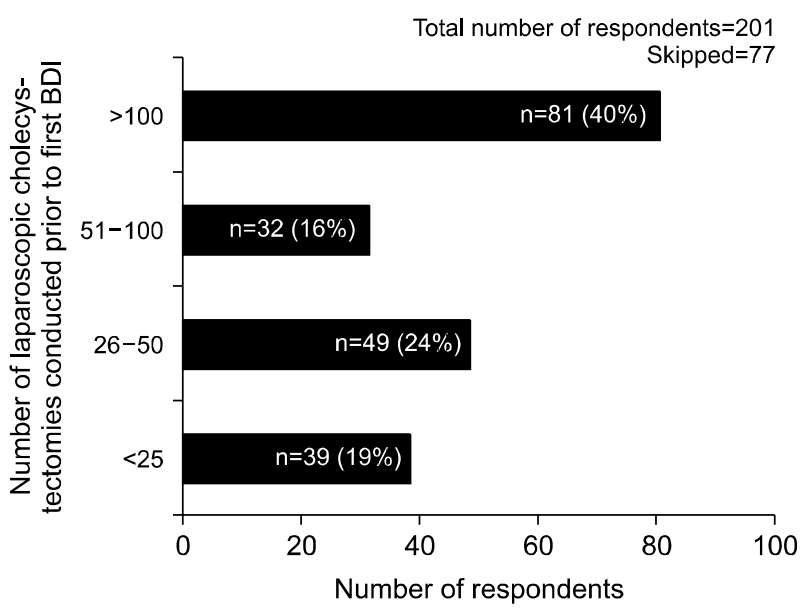

Fig. 3. Bar chart to show number of laparoscopic cholecystectomies conducted prior to the first bile duct injury. RYHJ, Roux-en-Y hepaticojejunostomy.

(78\%) affirmed to more than one BDI (Q 4). Fig. 2 depicts breakup of the number of BDIs experienced by respondents.

Majority i.e. 141/230 (61\%) experienced their first BDI within 5 years of their laparoscopy career, while 36/230 (15\%) experienced a BDI even after being in practice for $>10$ years (Q 5). Fig. 3 shows number of LCs performed by respondents before the first BDI (Q 6). BVI during BDI was reported by 14/201 (7\%) respondents (Q 7). Only $11 / 201$ (5\%) routinely use intraoperative cholangiography (IOC) at their centers (Q 8). Fig. 4 shows time of detection of the first BDI; 196/201 (97\%) of the respondents identified a BDI as bile leak either on-table or in the drain and only 5/201 (2\%) reported it manifesting as a benign biliary stricture on follow up (Q 9). The first BDI occurred in the hands of 125/201 (62\%) respondents when they were the operating surgeon. The respondent 


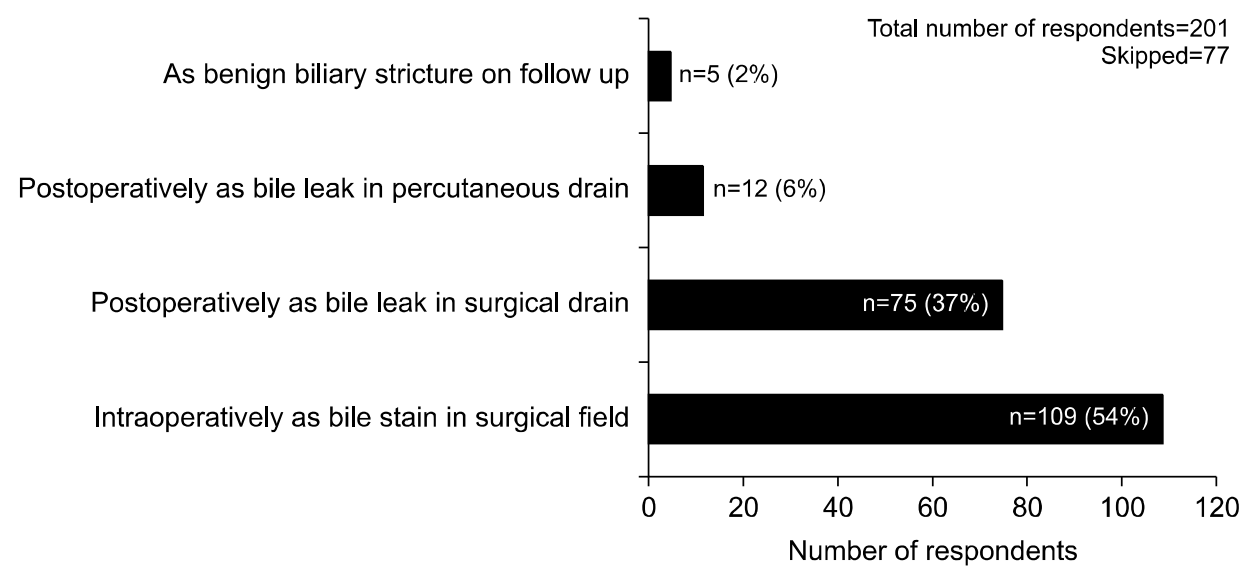

Total number of respondents $=201$

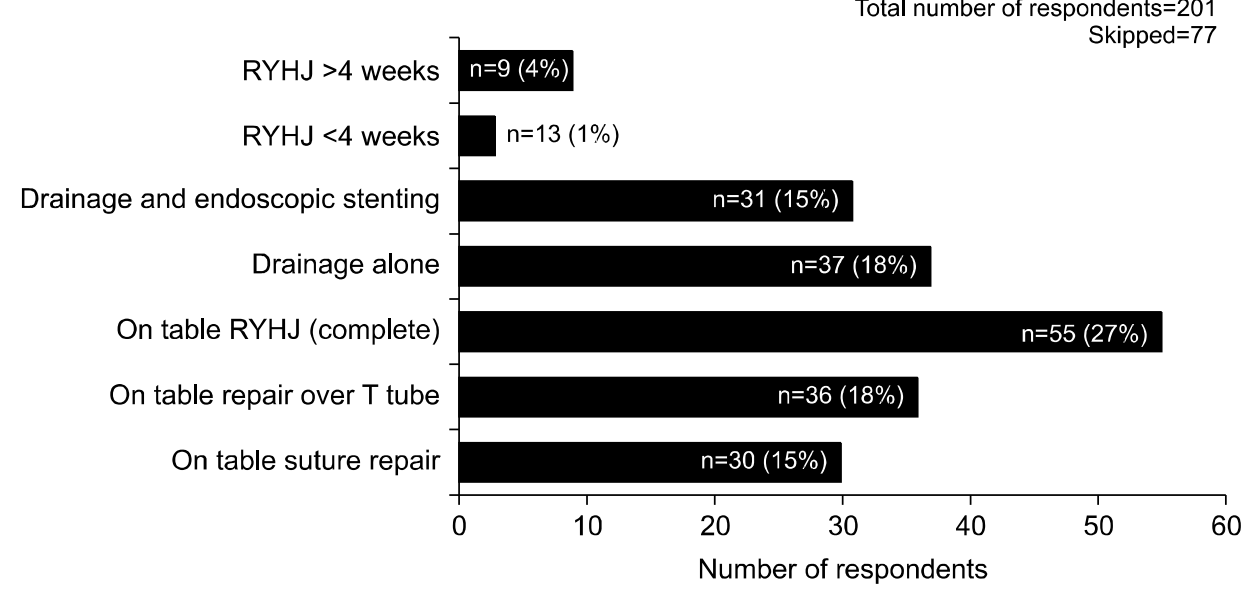

Fig. 4. Bar chart to show time of detection of the first bile duct injury.
Fig. 5. Bar chart to type of management strategy used by the respondents. RYHJ, Rouxen-Y hepaticojejunostomy. was assisting a senior surgeon in $39(19 \%)$ instances, assisting a junior surgeon in $12(6 \%)$ and was not scrubbed (but was the team leader) on 25 (12\%) occassions (Q 10). $161 / 201(80 \%)$ of the respondents decided to manage the BDI themselves and only 40/201 (20\%) referred the patient to another center ( $Q$ 11). Fig. 5 lists the management strategy used by respondent surgeons (Q 12). Table 1 shows a comparative analysis between respondents who opted to manage their BDI on their own vs. those who referred the patient to a higher center with regard to their nature of surgical practice, number of prior LC performed, satisfying criteria of a biliary surgeon and working in a biliary center as outlined in the questionnaire. Table 2 compares the specific type of management strategy of the BDI chosen by various groups of surgeons. 86/201 (43\%) respondents had had a BDI in laparoscopic converted to open or open cholecystectomy also (Q 13). 37/201 (18\%) respondents admitted to having a mortality arising out of a BDI (Q 14); these 37 deaths occurred in a total of 728
BDIs reported in the survey, resulting in a mortality rate of $5 \%$ in this survey. 13/201 (6\%) respondents have experienced a medico-legal case related to a BDI in their own hands (Q 15).

NOTE Not all numbers tally as all respondents did not answer all the questions.

\section{DISCUSSION}

Our web based survey, probably the first of its kind from India, showed that most of the respondents had experienced a BDI and most had experienced more than one BDI during LC in their career. Moreover, most of the injuring surgeons preferred to manage the BDI themselves and very few referred the patient to higher center for definitive management of the BDI. BDI was associated with significant mortality but litigation rate was not very high.

The response rate in our survey was $38 \%$ which compares with $43 \%$ in UK survey, ${ }^{9} 45 \%$ in US survey, ${ }^{5} 58 \%$ 
Table 1. Comparison between surgeons who opted to manage the duct injury themselves vs. surgeons who referred to a higher center

\begin{tabular}{|c|c|c|c|c|}
\hline \multicolumn{2}{|c|}{ Surgical practice and experience } & \multirow{2}{*}{$\begin{array}{l}\text { Self-managed } \\
\qquad \mathrm{n}=161 \\
20(69 \%)\end{array}$} & \multirow{2}{*}{$\begin{array}{c}\begin{array}{c}\text { Referred } \\
n=40\end{array} \\
9(31 \%)\end{array}$} & \multirow{2}{*}{$\begin{array}{c}\text { Total No. } \\
29\end{array}$} \\
\hline Nature of practice & $\begin{array}{l}\text { Individual nursing home based with } \\
\text { an assistant who is not post graduate in } \\
\text { general surgery }\end{array}$ & & & \\
\hline & $\begin{array}{l}\text { Private hospital with an assistant who is } \\
\text { post graduate in general surgery }\end{array}$ & $24(63 \%)$ & $14(37 \%)$ & 38 \\
\hline & Corporate hospital & $42(91 \%)$ & $4(9 \%)$ & 46 \\
\hline & $\begin{array}{l}\text { Teaching hospital } \\
\text { (medical college/central institute) }\end{array}$ & $75(85 \%)$ & $13(15 \%)$ & 88 \\
\hline \multirow{4}{*}{$\begin{array}{l}\text { Number of LC before } \\
\text { first BDI }\end{array}$} & $<25$ & $27(69 \%)$ & $12(31 \%)$ & 39 \\
\hline & $26-50$ & $36(73 \%)$ & $13(27 \%)$ & 49 \\
\hline & $51-100$ & $23(72 \%)$ & $9(28 \%)$ & 32 \\
\hline & $>100$ & $75(92 \%)$ & $6(8 \%)$ & 81 \\
\hline \multirow[t]{2}{*}{ Biliary surgeon } & Yes & $96(94 \%)$ & $6(6 \%)$ & 102 \\
\hline & No & $65(66 \%)$ & $34(34 \%)$ & 99 \\
\hline \multirow[t]{2}{*}{ Working in a biliary center } & Yes & $110(92 \%)$ & $9(8 \%)$ & 119 \\
\hline & No & $51(62 \%)$ & $31(38 \%)$ & 82 \\
\hline
\end{tabular}

LC, laparoscopic cholecystectomy; BDI, bile duct injury

Table 2. Type of management strategy of the bile duct injury chosen by various groups of surgeons

\begin{tabular}{|c|c|c|c|c|}
\hline Type of repair & $\begin{array}{c}\text { Individual surgeon in } \\
\text { nursing home } \\
n=29\end{array}$ & $\begin{array}{c}\text { Surgeons with } \\
<5 \text { year experience } \\
\text { with LC } \\
n=123\end{array}$ & $\begin{array}{c}\text { Non biliary surgeons } \\
\mathrm{n}=99\end{array}$ & $\begin{array}{c}\text { Working in } \\
\text { a non biliary center } \\
n=82\end{array}$ \\
\hline On table suture repair & $3(10 \%)$ & $18(15 \%)$ & $11(11 \%)$ & $7(9 \%)$ \\
\hline On table repair over $\mathrm{T}$ tube & $7(24 \%)$ & $19(15 \%)$ & $25(25 \%)$ & $23(28 \%)$ \\
\hline On table RYHJ & $9(31 \%)$ & $31(25 \%)$ & $17(18 \%)$ & $10(12 \%)$ \\
\hline Drainage alone & $6(21 \%)$ & $27(22 \%)$ & $21(21 \%)$ & $21(26 \%)$ \\
\hline Drainage + endoscopic stenting & $3(10 \%)$ & $22(18 \%)$ & $22(22 \%)$ & $17(21 \%)$ \\
\hline$\S \mathrm{RYHJ}<4$ weeks & $1(3 \%)$ & $2(2 \%)$ & $1(1 \%)$ & $2(2 \%)$ \\
\hline$\S \mathrm{RYHJ}>4$ weeks & 0 & $4(3 \%)$ & $2(2 \%)$ & $2(2 \%)$ \\
\hline \multicolumn{5}{|l|}{ Summary of management } \\
\hline $\begin{array}{l}\text { Drainage with or } \\
\text { without endoscopic stenting }\end{array}$ & $9(31 \%)$ & $49(40 \%)$ & $43(43 \%)$ & $31(39 \%)$ \\
\hline Repair of BDI & $20(69 \%)$ & $74(60 \%)$ & $56(57 \%)$ & $44(54 \%)$ \\
\hline
\end{tabular}

LC, laparoscopic cholecystectomy; RYHJ, roux-en-y hepaticojejunostomy; BDI, bile duct injury

in Italian survey, ${ }^{7} 61 \%$ in a multi-national survey ${ }^{10}$ and $75 \%$ in Canadian survey. ${ }^{6}$ A confidential mail-out questionnaire to gauge surgeons' perspective on BDI during LC had a response rate of $75 \%$, but received only 114 completed responses. ${ }^{6}$ An anonymous retrospective multicenter questionnaire-based survey mailed to 316 heads of surgical units had a response rate of $58 \%$ and reported on 235 BDIs. ${ }^{7}$ Our web-based survey had 278 responses from practicing surgeons who reported a total of 728 BDIs.

Although there are several surveys on prevalence of BDI, most include small number of respondents. The
Swedish survey interviewed 76 surgical departments which had reported a BDI, ${ }^{8}$ Canadian survey included 114 surgeons, ${ }^{6}$ British survey included 117 respondents $^{9}$ and in Italian survey, only 184 heads of surgical units responded. $^{7}$ We received responses from 278 surgeons; other surveys with larger number of respondents are the multi-national survey of 372 surgeons from Japan, Korea and Taiwan ${ }^{10}$ and US survey of 1,661 surgeons. ${ }^{5}$

Prevalence of BDI in our survey was $86 \%$ (78\% for more than one BDI). Most surgeons tend to exaggerate their successful results and understate complications. Since 
ours was a self-reported survey (and not an external audit) of a surgical complication, we believe actual prevalence rates are even higher. We had greater (42\%) participation from surgeons in teaching hospitals, half were biliary surgeons and more than $85 \%$ had $>5$ years' experience with LC. The general/laparoscopic surgical community which performs majority of LCs is likely to have more non-biliary surgeons working in non-biliary centers i.e. nursing homes or private hospitals. Prevalence of BDI is likely to be even higher in their hands than in our sample.

The $86 \%$ prevalence of BDI in our survey compares with $79 \%$ in Swedish survey, ${ }^{8} 72 \%$ (BDIs and near misses) in multi-national survey ${ }^{10}$ and $69 \%$ in Italian survey ${ }^{7}$ but is much higher than $53 \%$ prevalence in the Canadian survey, ${ }^{6} 45 \%$ in UK survey ${ }^{9}$ and $27-38 \%$ in US survey. ${ }^{5}$

Experience of surgeon is no protection against BDI during LC. While $60 \%$ of BDIs in our survey occurred during first 5 years of laparoscopic surgical practice, so-called 'learning curve', ${ }^{12}$ as many as $15 \%$ of our respondents reported their first BDI after 10 years in practice. About $40 \%$ of respondents had performed more than 100 LCs before their first BDI. This has been reported earlier too. One-third of 65 BDIs in Belgium occurred in the hand of experienced surgeons. ${ }^{13}$ In Canada, almost two-thirds of surgeons experienced a BDI after 100 cholecystectomies. ${ }^{6}$ Similarly, $30 \%$ of the BDIs reported from Spain occurred when the surgeon had performed over 200 cases. ${ }^{14}$ In USA too, one-third of 704 BDIs occurred in hands of surgeons who had performed $>200$ LCs. $^{5}$ These observations indicate that so called 'learning curve' in $\mathrm{LC}^{15}$ is a myth ${ }^{14}$ and BDIs reflect fundamental errors in technique of LC rather than experience. ${ }^{5,16,17}$ A national multicenter questionnaire survey in Italy, sent to 316 heads of surgical units, did not identify risk factors in $80 \%$ of BDIs and half of these occurred during LCs described as "technically easy". Hence no cholecystectomy can be considered as a simple routine procedure, immune to the risk of BDI. ${ }^{7}$ In survey from Japan, Korea and Taiwan, ${ }^{10}$ authors found prevalence rate of BDI reached $>80 \%$ among surgeons who had performed $>1,000$ cases.

We included bile leak as BDI in our questionnaire according to Strasberg's classification (Types A, C and D). ${ }^{18}$ Most surveys from West, citing decreasing incidence of BDI following LC, have identified BDI as only those biliary injuries which needed surgical intervention thus miss- ing out those injuries which were managed by drainage with or without endoscopic stenting. ${ }^{5,19}$ Others have included only those BDIs which were treated at same center where LC was done, missing out on injuries managed at other centers. ${ }^{20}$ Moreover, even so-called minor BDIs can cause severe morbidity and death. Academic Medical Center, Amsterdam, Netherlands, reported a total of 800 BDIs, 216 of these were Strasberg Type A injuries, but mortality in these 216 cases was as high as 9/216 (4.2\%). ${ }^{21}$

Only $2.5 \%$ of our respondents reported BBS subsequent to BDI. Bile leaks (on-table or postoperatively in the drain) are more likely to be remembered by the surgeon and hence reported as BDI. Patients having a complication like BBS following LC are likely to go elsewhere than to injuring surgeon. Tertiary level referral hospitals in India report large number of post-cholecystectomy $\mathrm{BBS}^{22,23}$

More than $2 / 3^{\text {rd }}$ of our respondents, many of whom were non-biliary surgeons working in non-biliary centers, opted to manage the BDI on their own, including on-table repairs and RYHJ. Some of these may have been minor injuries which could be managed with simple measures. It could also reflect mentality of the injuring surgeon to "fix the leak" then and there and thus avoid postoperative morbidity and litigation related to bile leak. This is worldwide experience, ${ }^{8}$ despite suggestions of better outcomes if the patient is referred to a higher center. ${ }^{24}$ While immediate repair (end-to-end repair over $\mathrm{T}$ tube or RYHJ) by a biliary surgeon may be acceptable, it is not recommended for a non-biliary surgeon working in non-biliary center e.g. nursing home or private hospital to repair a BDI. Such attempts are rarely successful, cause more (higher) injury to the bile duct, can cause vascular injury and thus make future repair challenging even for biliary surgeon. ${ }^{25}$ Immediate repair by the injuring general/laparoscopic non-specialist surgeon in the injuring hospital itself is one of the risk factors for litigation being filed and decided against the surgeon. ${ }^{26}$

Associated BVI was reported by $7 \%$ of surgeons. This probably reflects on-table assessment based on intraoperative blood loss. Most surgeons would not routinely do vascular evaluation (e.g. Doppler, CT angiography or MR angiography), especially in setting of acute BDI. Figures quoted in literature for BVI vary from $0.25 \%{ }^{27}$ to $36 \%{ }^{28}$ depending on method used for documentation.

BDI can cause mortality due to uncontrolled intraabdo- 
minal and systemic sepsis. We recorded a mortality of 5\% (37 deaths in a total of 728 BDIs). Since ours is a self-reported survey by a very select group of surgeons and not a longitudinal study, the actual figures can be even higher. Way back in 1994, Gouma and $\mathrm{Go}^{29}$ reported mortality of $7.8 \%$ in 77 patients with BDI. In another report from India, Mishra et al. ${ }^{30}$ reported 6 deaths in 137 patients with BDI. It was $3.5 \%$ in a single large institution (Academic Medical Center, Amsterdam, Netherlands) experience of 800 BDIs. $^{31}$ BDI also increases life-time risk of biliary-related death. In a recent analysis of 711,454 cholecystectomies in USA, patients with bile leak were more likely $(2.4 \%$ vs. $1.4 \%)$ to die at one year than those who did not and those with BDI were more likely (7.2\% vs. $1.3 \%$ ) to die at one year than those who did not. ${ }^{1}$

Fortunately, litigation rates for BDI during LC are low in India. Only $6 \%$ of responding surgeons had medico-legal cases filed against them for BDI caused during LC. This is much lower prevalence than reported from other countries. In a report from the Great Britain and Ireland, $22 \%$ of 117 respondents reported a medico-legal experience following LC. ${ }^{9}$

In this web-based survey of surgeons, probably first such from India a LMIC, we found most surgeons have had at least one BDI during LC. BDI occurred even in the hands of "experienced" biliary surgeons. Many nonbiliary surgeons working in non-biliary centers still attempt to repair the BDI themselves, contrary to the recommendations of various guidelines. BDI carries significant risk of death; mortality of BDI in this survey was $5 \%$. BDI resulted in litigation against the surgeon though the rates were lower than in the West.

\section{ACKNOWLEDGEMENTS}

The authors are grateful to the 278 surgeons who accepted our request to respond to this survey. Thanks are also due to Dr Latika Gupta Assistant Professor of Clinical Immunology, SGPGIMS, Lucknow India for helping us with e-survey.

\section{CONFLICT OF INTEREST}

The authors have nothing to disclose.

\section{ORCID}

Supriya Sharma: https://orcid.org/0000-0002-3183-0483

Anu Behari: https://orcid.org/0000-0003-1522-0869

Ratnakar Shukla: https://orcid.org/0000-0002-3222-0898

Mukteshwar Dasari:

https://orcid.org/0000-0002-8957-9340

Vinay K. Kapoor: https://orcid.org/0000-0001-6953-7947

\section{AUTHOR CONTRIBUTIONS}

Conceptualization: SS, VKK. Data curation: SS, RS, MD. Data Analysis: SS, AB, RS, MD, VKK. Original Writing: SS, VKK. Writing review and editing: SS, AB, VK.

\section{REFERENCES}

1. Fong ZV, Pitt HA, Strasberg SM, Loehrer AP, Sicklick JK, Talamini MA, et al. Diminished survival in patients with bile leak and ductal injury: management strategy and outcomes. J Am Coll Surg 2018;226:568-576.e1.

2. Törnqvist B, Strömberg C, Persson G, Nilsson M. Effect of intended intraoperative cholangiography and early detection of bile duct injury on survival after cholecystectomy: population based cohort study. BMJ 2012;345:e6457.

3. Waage A, Nilsson M. Iatrogenic bile duct injury: a population-based study of 152776 cholecystectomies in the Swedish Inpatient Registry. Arch Surg 2006;141:1207-1213.

4. Pucher PH, Brunt LM, Davies N, Linsk A, Munshi A, Rodriguez $\mathrm{HA}$, et al. Outcome trends and safety measures after 30 years of laparoscopic cholecystectomy: a systematic review and pooled data analysis. Surg Endosc 2018;32:2175-2183.

5. Archer SB, Brown DW, Smith CD, Branum GD, Hunter JG. Bile duct injury during laparoscopic cholecystectomy: results of a national survey. Ann Surg 2001;234:549-558; discussion 558-559.

6. Francoeur JR, Wiseman K, Buczkowski AK, Chung SW, Scudamore CH. Surgeons' anonymous response after bile duct injury during cholecystectomy. Am J Surg 2003;185:468-475.

7. Nuzzo G, Giuliante F, Giovannini I, Ardito F, D'Acapito F, Vellone $\mathrm{M}$, et al. Bile duct injury during laparoscopic cholecystectomy: results of an Italian national survey on 56591 cholecystectomies. Arch Surg 2005;140:986-992.

8. Rystedt J, Lindell G, Montgomery A. Bile duct injuries associated with 55,134 cholecystectomies: treatment and outcome from a national perspective. World J Surg 2016;40:73-80.

9. Gordon-Weeks A, Samarendra H, de Bono J, Soonawalla Z, Silva M. Surgeons opinions of legal practice in bile duct injury following cholecystectomy. HPB (Oxford) 2017;19:721-726.

10. Iwashita $Y$, Hibi $T$, Ohyama $T$, Umezawa A, Takada $T$, Strasberg SM, et al. Delphi consensus on bile duct injuries during laparoscopic cholecystectomy: an evolutionary cul-de-sac or the birth pangs of a new technical framework? J Hepatobiliary Pancreat Sci 2017;24:591-602.

11. Eysenbach G. Improving the quality of web surveys: the Checklist for Reporting Results of Internet E-Surveys (CHERRIES). 
J Med Internet Res 2004;6:e34.

12. McMahon AJ, Fullarton G, Baxter JN, O’Dwyer PJ. Bile duct injury and bile leakage in laparoscopic cholecystectomy. $\mathrm{Br} \mathrm{J}$ Surg 1995;82:307-313.

13. Gigot J, Etienne J, Aerts R, Wibin E, Dallemagne B, Deweer $\mathrm{F}$, et al. The dramatic reality of biliary tract injury during laparoscopic cholecystectomy. An anonymous multicenter Belgian survey of 65 patients. Surg Endosc 1997;11:1171-1178.

14. Calvete J, Sabater L, Camps B, Verdú A, Gomez-Portilla A, Martín J, et al. Bile duct injury during laparoscopic cholecystectomy: myth or reality of the learning curve? Surg Endosc 2000;14:608-611.

15. The Southern Surgeons Club. A prospective analysis of 1518 laparoscopic cholecystectomies. N Engl J Med 1991;324:10731078.

16. Fullum TM, Downing SR, Ortega G, Chang DC, Oyetunji TA, Van Kirk K, et al. Is laparoscopy a risk factor for bile duct injury during cholecystectomy? JSLS 2013;17:365-370.

17. Way LW, Stewart L, Gantert W, Liu K, Lee CM, Whang K, et al. Causes and prevention of laparoscopic bile duct injuries: analysis of 252 cases from a human factors and cognitive psychology perspective. Ann Surg 2003;237:460-469.

18. Strasberg SM, Hertl M, Soper NJ. An analysis of the problem of biliary injury during laparoscopic cholecystectomy. J Am Coll Surg 1995;180:101-125.

19. Halbert C, Pagkratis S, Yang J, Meng Z, Altieri MS, Parikh P, et al. Beyond the learning curve: incidence of bile duct injuries following laparoscopic cholecystectomy normalize to open in the modern era. Surg Endosc 2016;30:2239-2243.

20. Mangieri CW, Hendren BP, Strode MA, Bandera BC, Faler BJ. Bile duct injuries (BDI) in the advanced laparoscopic cholecystectomy era. Surg Endosc 2019;33:724-730.

21. Harboe KM, Bardram L. The quality of cholecystectomy in Denmark: outcome and risk factors for 20,307 patients from the national database. Surg Endosc 2011;25:1630-1641.
22. Pottakkat B, Vijayahari R, Prasad KV, Sikora SS, Behari A, Singh RK, et al. Surgical management of patients with post-cholecystectomy benign biliary stricture complicated by atrophy-hypertrophy complex of the liver. HPB (Oxford) 2009;11:125-129.

23. Javed A, Shashikiran BD, Aravinda PS, Agarwal AK. Laparoscopic versus open surgery for the management of post-cholecystectomy benign biliary strictures. Surg Endosc 2020. doi: 10.1007/s00464-020-07496-6. [in press]

24. Stewart L, Way LW. Bile duct injuries during laparoscopic cholecystectomy. Factors that influence the results of treatment. Arch Surg 1995;130:1123-1128; discussion 1129.

25. Bansal VK, Misra M, Agarwal AK, Agrawal JB, Agarwal PN, Aggarwal S, et al. SELSI consensus statement for safe cholecystectomy-prevention and management of bile duct injury-Part B. Indian J Surg 2019. doi: 10.1007/s12262-019-01994-1. [in press]

26. Kapoor VK. Medico-legal aspects of bile duct injury. J Minim Access Surg 2016;12:1-3.

27. Deziel DJ, Millikan KW, Economou SG, Doolas A, Ko ST, Airan MC. Complications of laparoscopic cholecystectomy: a national survey of 4,292 hospitals and an analysis of 77,604 cases. Am J Surg 1993;165:9-14.

28. Alves A, Farges O, Nicolet J, Watrin T, Sauvanet A, Belghiti $\mathrm{J}$. Incidence and consequence of an hepatic artery injury in patients with postcholecystectomy bile duct strictures. Ann Surg 2003;238:93-96.

29. Gouma DJ, Go PM. Bile duct injury during laparoscopic and conventional cholecystectomy. J Am Coll Surg 1994;178:229-233.

30. Mishra PK, Saluja SS, Nayeem M, Sharma BC, Patil N. Bile duct injury-from injury to repair: an analysis of management and outcome. Indian J Surg 2015;77(Suppl 2):536-542.

31. Booij KAC, de Reuver PR, van Dieren S, van Delden OM, Rauws EA, Busch OR, et al. Long-term impact of bile duct injury on morbidity, mortality, quality of life, and work related limitations. Ann Surg 2018;268:143-150. 